\title{
Pemrograman Rumah Sakit Tali Kasih
}

NPM

:19411084

NAMA $\quad$ :Tenti Ristiana Ningrum

PRODI :Sistem informasi

FAKULTAS :Fakultas Ilmu Komputer

EMAIL :tentiristiananingrum30@gmail.com

\section{$\underline{\text { SOAL TUGAS : }}$}

1. Buatlah Program dengan ketentuan sebagai berikut:

Input :

kode pasien $=$ PSO003

Kode Kamar $=4444$

Lama Menginap $=5$ hari

Kode Dokter $=$ DKO03

\begin{tabular}{|l|l|l|}
\hline Kode Pasien & Status Pasien & Biaya Daftar Pasien \\
\hline PS0001 & Pasien Baru & Rp. 500.000 \\
\hline PS0002 & Pasien Lama & Rp. 400.000 \\
\hline PS0003 & Pasien BPJS & Rp. 300.000 \\
\hline PS0004 & Pasien Askes & Rp. 200.000 \\
\hline
\end{tabular}

\begin{tabular}{|l|l|l|}
\hline Kode Kamar & Nama Kamar & Biaya Kamar \\
\hline 1111 & Kamar Melati & Rp. 1.000 .000 \\
\hline 2222 & Kamar Mawar & Rp. 2.000.000 \\
\hline 3333 & Kamar Dahlia & Rp. 3.000.000 \\
\hline 4444 & Kamar Anggrek & Rp. 4.000.000 \\
\hline 5555 & Kamar Tulip & Rp. 5.000 .000 \\
\hline
\end{tabular}

\begin{tabular}{|l|l|}
\hline Lama Menginap & Diskon \\
\hline$>10$ Hari & $50 \%$ dari Biaya Kamar \\
\hline$>8$ Hari & $40 \%$ dari Biaya Kamar \\
\hline$>6$ Hari & $30 \%$ dari Biaya Kamar \\
\hline$>4$ Hari & $20 \%$ dari Biaya Kamar \\
\hline$>+1$ & $10 \%$ dari Biaya Kamar \\
\hline
\end{tabular}




\begin{tabular}{|l|l|l|}
\hline Kode Dokter & Nama Dokter & Biaya Pemeriksaan \\
\hline DK001 & DR. Andi & Rp. 500.000 \\
\hline DK002 & DR. Joko & Rp. 400.000 \\
\hline DK003 & DR. Karni & Rp. 300.000 \\
\hline DK004 & DR. Amin & Rp. 200.000 \\
\hline DK005 & DR. Udin & Rp. 100.000 \\
\hline
\end{tabular}

Total Bayar = Biaya Daftar Pasien + Biaya Kamar + Biaya Pemeriksaan - Diskon

Output (Tampilkan) =

Status Pasien

Biaya daftar Pasien

Nama Kamar

Biaya Kamar

Nama Dokter

Biaya Pemeriksaan

Diskon

Total Bayar 
SOURCE CODE / KODING PROGRAM (KETIK DIBAWAH INI)

public class hospital \{

public static void main(String [] args)\{

String kdepasien="PS0003",kddokter="DK003";

int kdekmr=4444, lmamnginap $=5$;

String sttspsien,nmakmr,nmadr;

int biayadftr,biayakmr,biayapmriksaan;

double diskon;

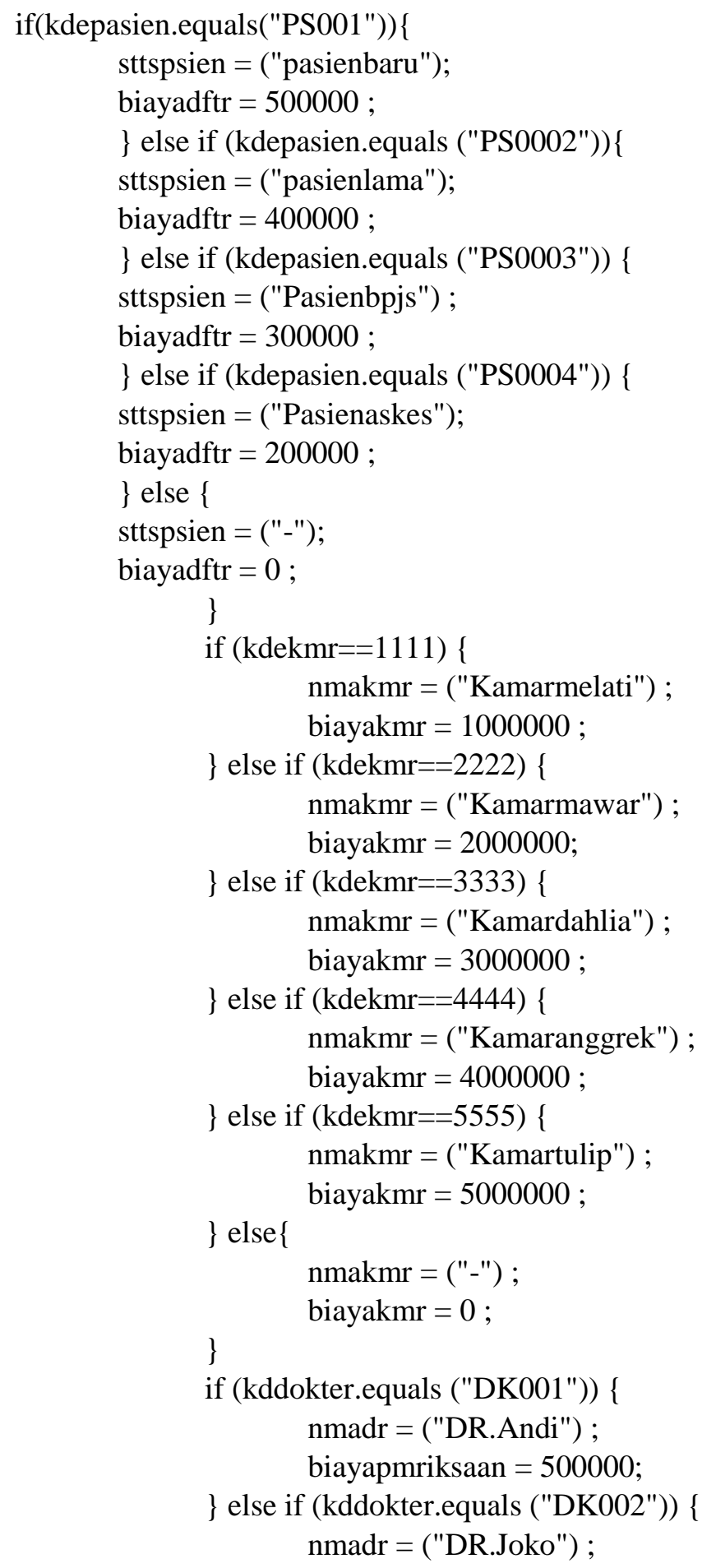




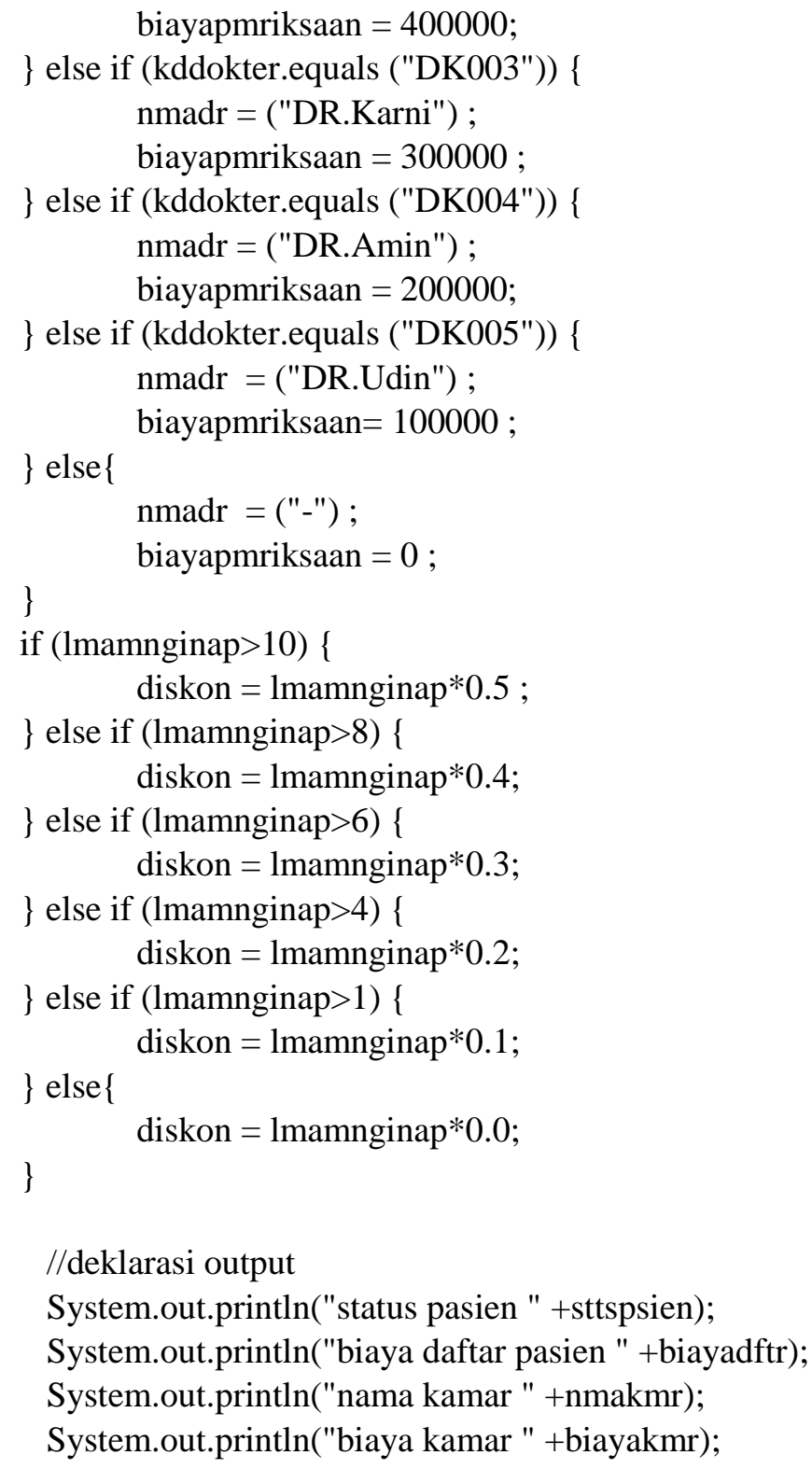




\section{PENJELASAN SOURCE CODE (KETIK DIBAWAH INI)}

$>$ Public adalah kode akses yang bersifat umum.atau dalam artian bahwa kodingan tersebut dapat diakses oleh umum.

$>$ Class adalah cetakan untuk menciptakan suatu instan dari objeck

> Static adalah salah satu jenis modifier di java yang digunakan agar suatu atribut ataupun method dapat diakses oleh kelas atau obejek tanpa harus melakukan instansiasi terhadap kelas tersebut.

$>$ Void adalah method yang tidak dimiliki nilai kembali,biasanya digunakan tidak untuk mencari nilai dalam suatu operasi.

$>$ Main menerima sebuah argument arry bertipe string .

$>$ Args tugas nya untuk menyimpan nilai argumen

$>$ public static void main(String [] args $)\{$ “ maka pemrograman java tidak akan berjalan atau akan terjadi error.

$>$ String adalah type data text.

$>$ int adalah type data angka bilangan bulat bukan pecahan atau desimal..

$>$ Pada variabel yang berbentuk text dimasukan pada type data String meliputi text murni atau kombinasi angka dan text (apabila angka dan text telah berkombinasi maka type data nya adalah text bukan angka.

$>$ If untuk data disamping tidak akan terpanggil karena tidak sesuai dengan deklarasi variabel yang diberi nilai diatas atau yang saya beri garis bawah,

$>$ Else if untuk data disamping akan terpanggil karena sesuai dengan data diatas.

$>$ Buka tutup kurung kurawal \{\} dibawah if dan else if adalah data yang akan di tampilkan saat variabel disamping if atau else if sesuai dengan deklarasi variabel diatas yang telah diberi nilai.

> "//" tanda tersebut berguna untuk memberika deskripsi untuk kodingan kita atau bisa juga mematikan kodingan apabila kita tidak ingin mengaktifkan kodingnya.

$>$ Lalu dibawah nya merupakan rumus yang akan kita hitung atau proses penghitungan.

> Untuk kodingan System.out.println berguna untuk menampilkan data yang akan kita tampilkan. pada tanda petik dua merupakan deskripsi yang akan muncul pada tampilan yang ada di cmd/terminal. Tanda + merupakan variabel yang akan dipanggil untuk di tampilkan di cmd/terminal.

> Untuk tanda “; ; berguna untuk memberikan proses telah berakhir untuk satu baris pemrograman. 


\section{FLOWCHART PROGRAM}

\section{Start}

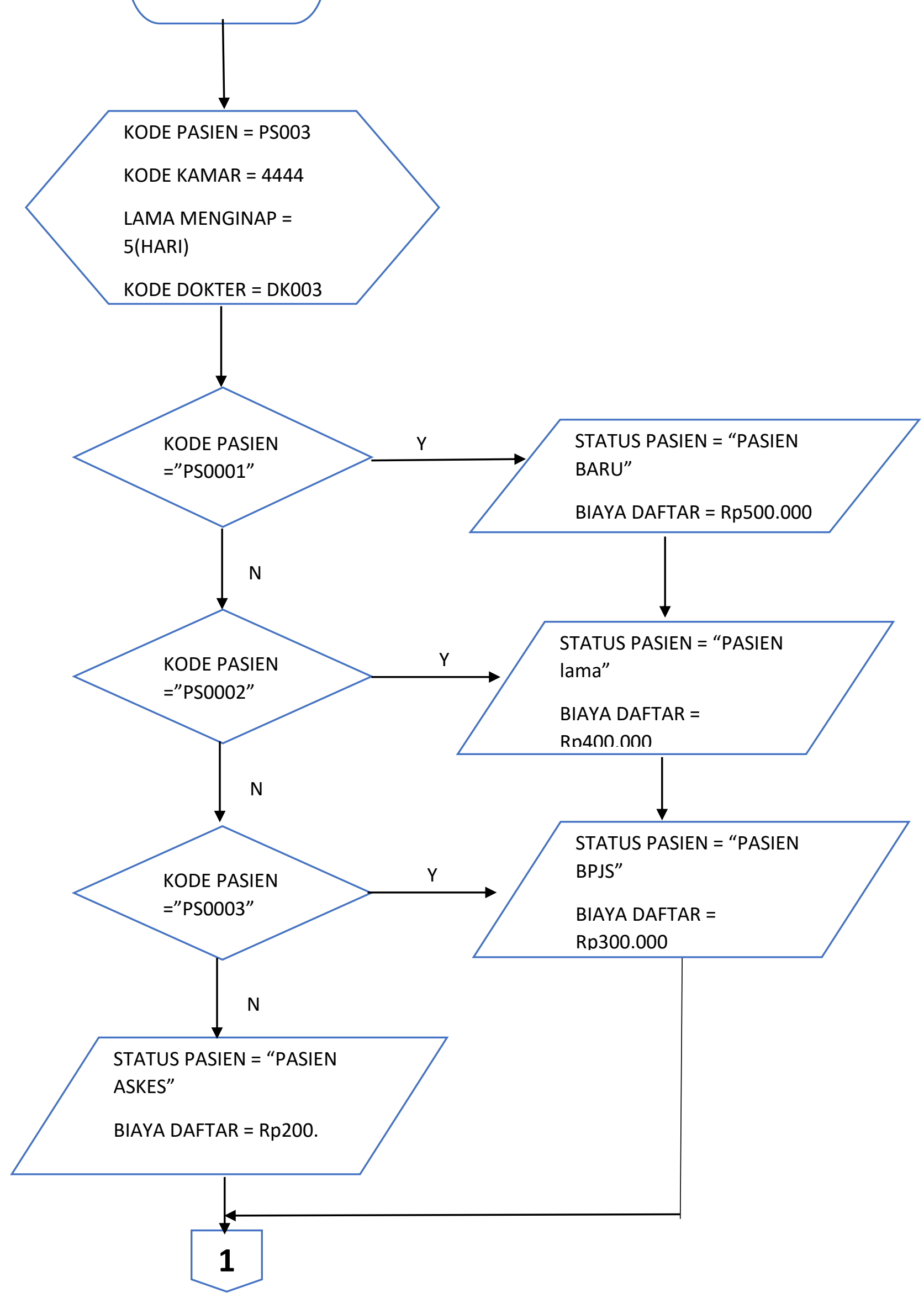




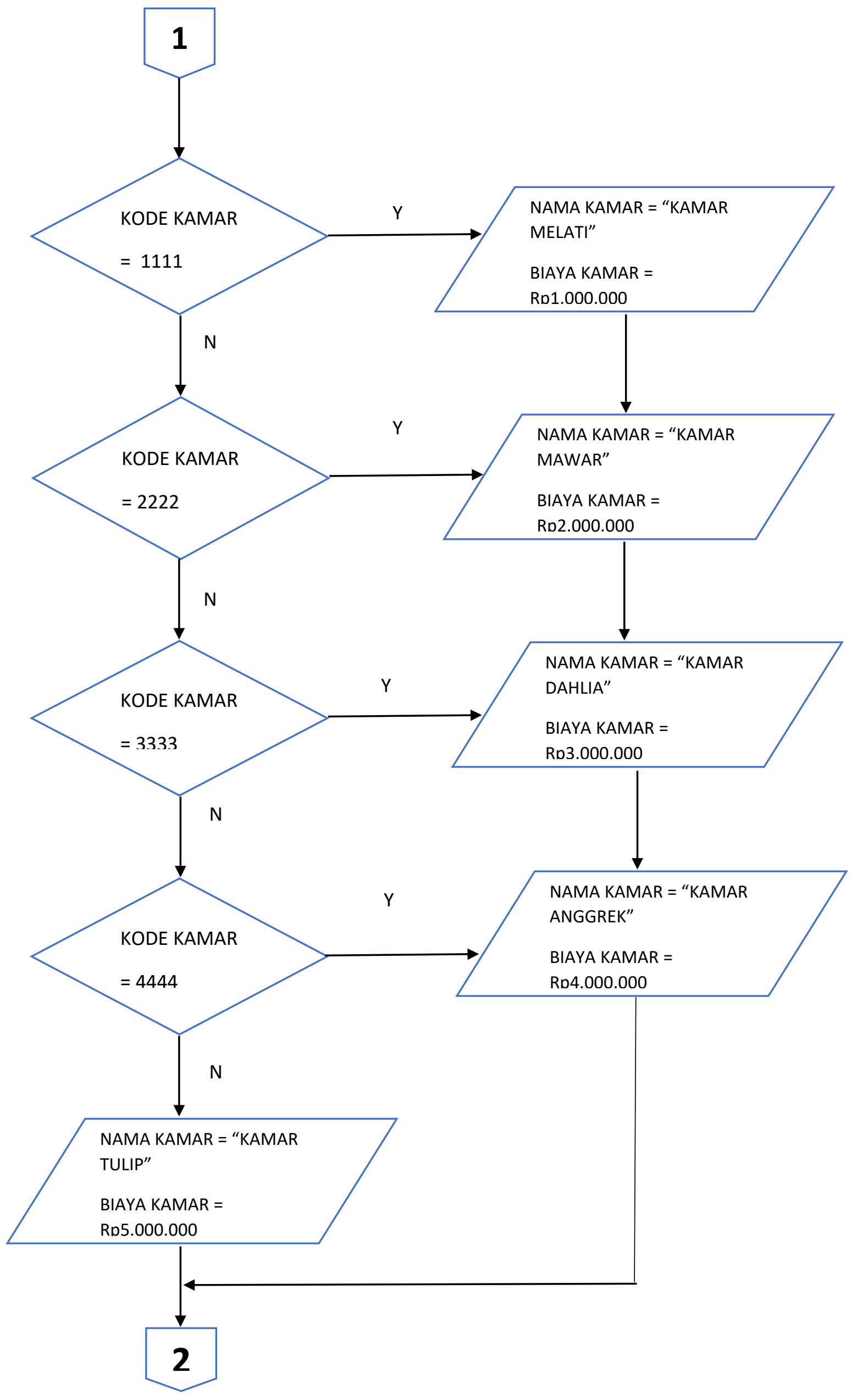




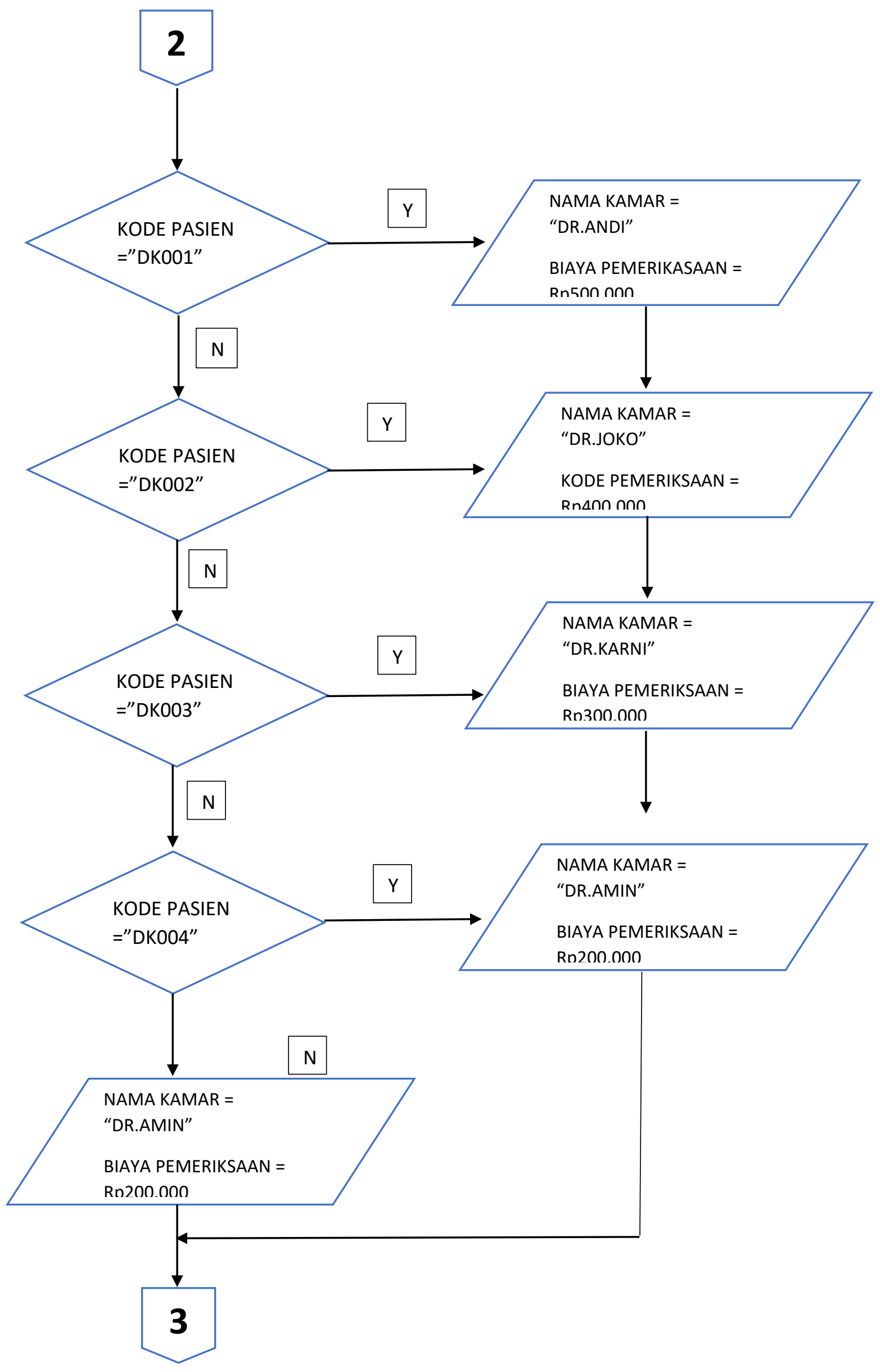




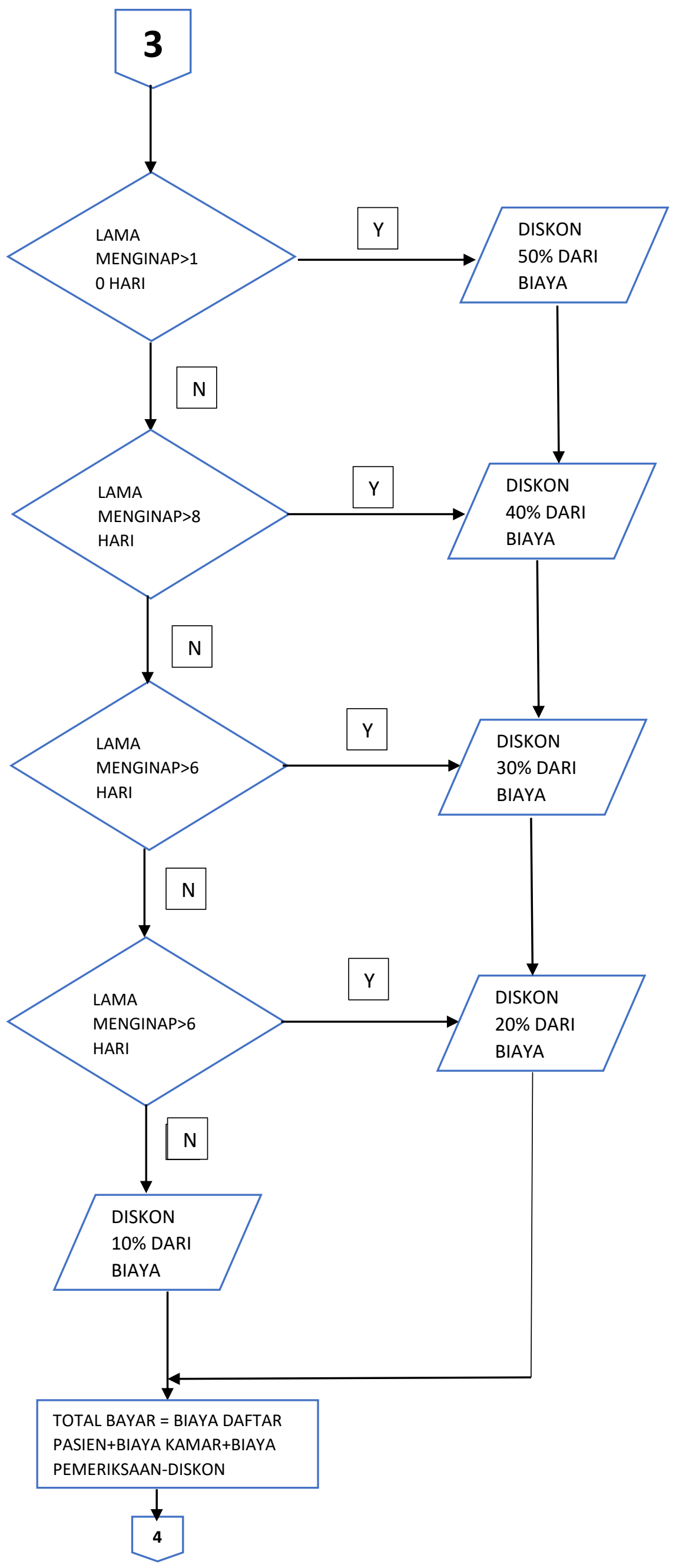




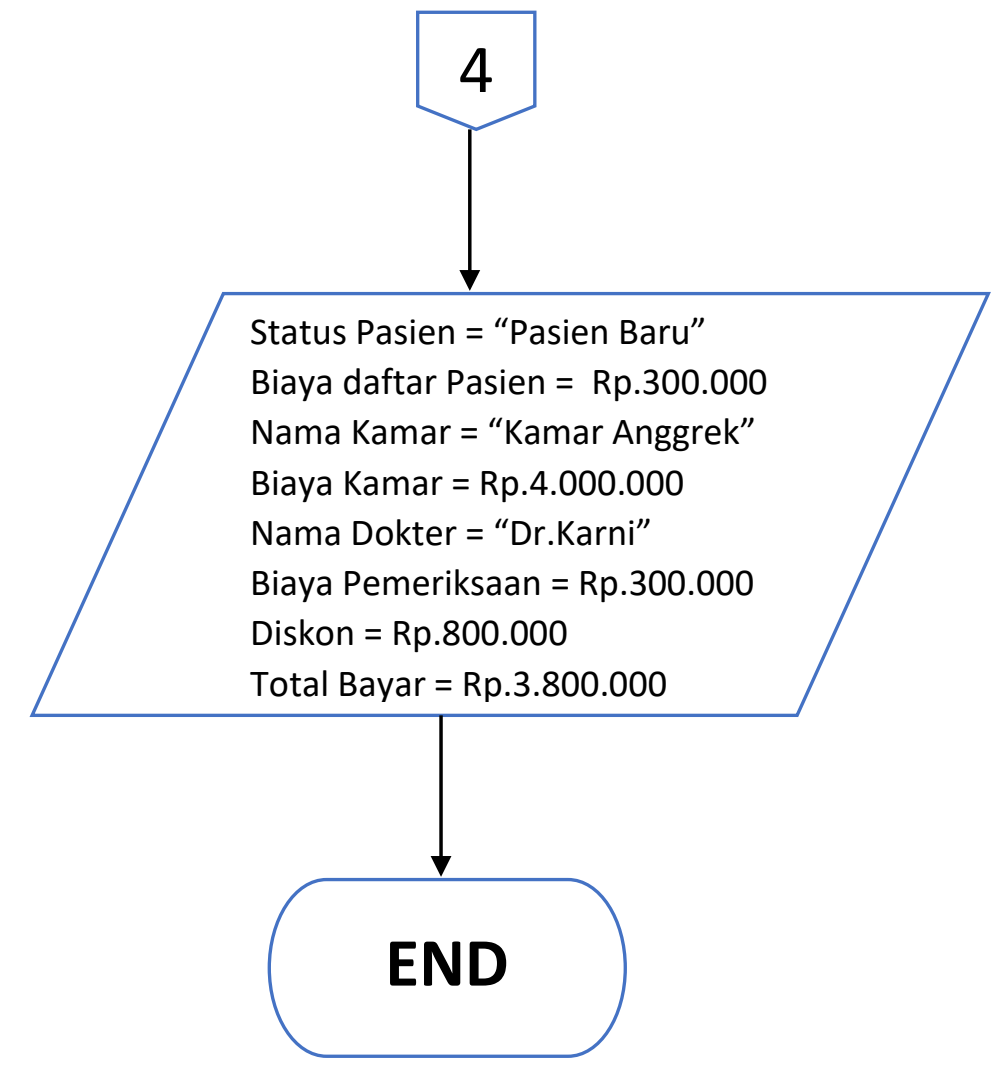




\section{REFERENSI :}

Endra, R. Y. (2019, October 29). Belajar Mudah Algoritma dan Pemograman Java. Retrieved from osf.io/v7yfn

Endra, R. Y. (2019, October 29). Internet of Things. Retrieved from osf.io/4h8sf 